\title{
Design of a Robotic ARM for Teaching InTEgrated Design
}

\author{
Martha Kafuko*, Ishwar Singh**and Tom Wanyama*** \\ Department of Mechanical Engineering*, School of Engineering Technology**, McMaster University \\ Hamilton, Ontario \\ kafukom@mcmaster.ca* \\ ishwar.singh@mohawkcollege.ca** \\ wanyama@mcmaster.ca***
}

\begin{abstract}
Automation systems are generally made up of three main subsystems, namely mechanical, electrical and software. The interactions among these components affect the integrated system in terms of reliability, quality, scalability, and cost. Therefore, it is imperative that the three components of automation systems are designed concurrently through an integrated design paradigm. This leads to the need to teach integrated design concepts to students in programs such as process automation, electrical and computer engineering, and mechanical engineering. However, due to the time constraint, it is almost impossible to run full integrated design class projects. Therefore, instructors have to decide on the parts of the design process that their class projects have to focus on, and the parts that have to be reviewed for the completeness of the integrated design process. In this paper we present the design and implementation of a microcontroller based, 3 D printable, low cost robotic arm suitable for teaching integrated design. Moreover, the paper presents how the robotic arm design is used in an integrated design project of an Industrial Networks and Controllers course. Since the focus of this course is the electrical and software subsystems of the robotic arm, and we do not have enough time to do a full design, students review the design of the robotic arm presented in this paper and use it to either $3 D$ print the robotic arm or purchase the mechanical subsystem of the robotic arm that meets the specification.
\end{abstract}

Keywords: Teaching integrated design, automation systems, project based learning, integrated design and 3D printing, concurrent system design.

\section{INTRODUCTION}

The design process is one of the most extensive and essential processes that needs to be carried out in order to produce working devices that meet the needs of consumers. From determining the problem statement and metrics, to deciding the most promising design and creating prototypes, the design process guides designers to capture, integrate, and generate all the information required to make new products. In the design of automation systems, the design process has to address the interactions among the mechanical, electrical, and software components of systems in order to develop systems that have acceptable reliability, quality, scalability, and cost characteristics. This is achieved by designing the three components of automation systems concurrently through an integrated design paradigm [8]. Consequently, it is necessary to teach integrated design concepts to students in programs such as process automation, electrical and computer engineering, and mechanical engineering.

Integrated design is one of the engineering courses that needs to be taught through the experiential learning techniques, such as course projects. However, because of time and cost limitations, it is almost impossible to run full integrated design class projects. Therefore, instructors have to decide based on their engineering fields, the parts of the design process that their class projects have to focus on, and the parts that have to be reviewed for the completeness of the integrated design process. For example, a mechanical engineering instructor may want to focus on the mechanical design of an automation system, while an electrical engineering instructor may simply review the mechanical design of the system and then focus on its electrical design. The availability of low cost hardware tools such as 3D printing and microcontrollers, free software tools such as Arduino Development Environment (ADE) or Code Composer Studio for TI's Launchpad, it is easy for instructors to integrate projects into their integrated design courses.

In this paper we present the design of a $3 \mathrm{D}$ printable robotic arm. Moreover, the paper explains how we use it to support experiential learning through an integrated design project of an Industrial Networks and Controllers course in the process automation stream of the Bachelor of Engineering Technology program at McMaster University. The rest of the paper is arranged as follows: 
Section 2 presents what motivated us to use a robotic arm in our project. Section 3 deal with the design of the robotic arm while Section 4 presents how we use the robotic arm in the integrated design project of the course Industrial Networks and Controllers of the Process Automation program at McMaster University. We present the conclusion in Section 5.

\section{MOTIVATION}

Robots fall under the category of mechatronic engineering products that have mechanical, electrical and software components $[2,4,10]$. Therefore, an integrated design project involving the design of a robot allows students to participate in hands-on practice through which they can learn many engineering concepts and applications [4]. Moreover, it is important to teach process automation students robot design because the use of robotics in industry is popular due to its ability to lower production costs. In fact, the use of robots is currently extending in what were previously non-traditional areas such as the food industry as well as farming and agriculture [6]. This trend is expected to continue as companies seek to improve product quality and lower production cost through automation.

The availability of low cost hardware tools such as 3D printing and microcontrollers, as well as low cost software tools such as Arduino Development Environment (ADE), make it is easy to teach practical skills required to support the robotics industry at universities, colleges and high schools. For example, Juliana et al [3] have developed a low cost, 3D printable, multi-purpose, modular robotic arm for education and unmanned platforms, while Soriano et al [1] present a low cost platform for Automatic Control Education Based on Open Hardware. In addition, Singh et al [7] were able to implement and test their gripper for a pick and place robot because of the low cost associated with its production. These developments in technology, as well as the need to teach both integrated design and robot design, motivated us to carry out the project report in this paper.

\section{ROBOTIC ARM DESIGN}

The Industrial Networks and Controllers course in the process automation stream of the bachelor of technology program at McMaster University focuses on the following areas of robot design:

- Selection of controllers, user interfaces, motors, sensors and other electrical components.

- Dimensioning of power supplies.

- Integration of electrical components.

- Establishment of the process into which the robot is to be integrated.
- Development of the software program for the robot. This means that the design of the mechanical components of the robot is outside of the focus of our course. Yet, the motors have to meet the mechanical specification of the robot, and installation of electrical components is affected by the mechanical design. Therefore, our students review the mechanical design so as to get insight into the mechanical limitations of the robot, such as:

- Why motors of a particular specification have to be selected.

- The maximum load the robot can carry.

- The shape of the robot.

\subsection{Mechanical Design}

We designed a pick and place robotic arm that can carry a maximum weight of 150 grams. Moreover, we wanted the arm to be easy to manufacture, construct and cost no more than $\$ 250$. In order to ensure that the produced design met the objectives, the following design criteria were developed:

- Functionality: The arm should have the ability to lift, move, lower and release an object while closely mimicking the motion of the human arm with full extension. Any device that can perform the required motions to pick and place an object that is less than or equal to 150 grams would have met the requirements of this criterion.

- Consistency/Reliability: The device should be able to consistently pick up and place objects in a smooth manner. I.e. the motion of the device should be smooth enough in order to not drop the objects that are being lifted. Therefore, any device that is able to lift and move an object from one place to another without losing any grip would meet the criteria.

- Manufacturability: The device should use readily available material or material that can easily be obtained by students in order to meet the requirements of this criterion.

- Easily constructible: The device should not consume a lot of time to assemble (maximum one hour). The fasteners should be easy to access with standard tools. Thus, any device that has less number of parts and uses standard parts will meet this requirement.

- Cost: The design that is used should use materials that cost no more than $\$ 250$.

These design criteria were used in the evaluation and ranking of the design options, and in the analysis stage of the design process. Moreover, students who may want to 
buy off-the-shelf robotic arms use the criteria to evaluate the available alternatives.

3.1.1 Calculations. During the design analysis stage we carried out a number of calculations to specify the motors. These calculations were based on simple kinematics as well as the following assumptions:

- The weight that each segment of the arm experiences is located along the center axis.

- The load's weight is evenly distributed around the center.

- The length of each segment is determined from one center point to the next.

- All Pieces are solid rectangular prisms for the purposes of determining an estimated moment of inertia.

- The weight of each joint is determined by choosing a standard sized motor that might be used. In this case, the motors chosen in Table 1.

- Lastly, the mass of each piece is estimated using SolidWorks "mass properties" evaluation.

These assumptions resulted into a system of forces shown in Figure 1.

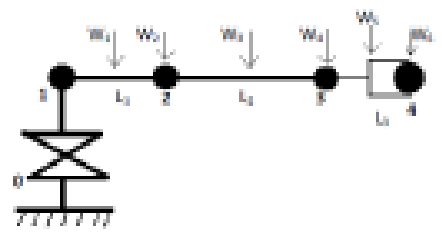

Fig. 1. Free Body Diagram of the Robotic Arm.

Equation 1 is an example of the calculations that were carried out to determine the torque of the shoulder joint and elbow joint motors.

$$
\begin{gathered}
T_{1}=\frac{L_{1} W_{1}}{2}+L_{2} W_{2}+\left(\frac{L_{2}}{2}+L_{1}\right) W_{3}+\left(L_{1}+L_{2}\right) W_{4}+\left(L_{1}+L_{2}+\frac{L_{3}}{2}\right) V_{5}+\left(L_{1}+L_{2}+L_{3}\right) W_{6} \\
\tau_{1}-9.8049 \mathrm{Nm}
\end{gathered}
$$

The torque of gripper, base and wrist joint motors was calculated using Equation 2.

$$
\begin{gathered}
\tau=i \alpha \\
\tau_{0}=\frac{1}{12} m\left(l^{2}+w^{2}\right) \alpha
\end{gathered}
$$

Where $m$ is the sum of the mass of all the pieces on the arm, $l$ is the length and $\mathrm{w}$ is the width of the arm, and $\alpha$ is the angular acceleration that was predetermined to be $0.785 \mathrm{rad} / \mathrm{s}^{2}$ for the base and wrist joint motors, and $0.1963 \mathrm{rad} / \mathrm{s}^{2}$ for the gripper motor.

Based on calculations such as those presented above, the torque shown in Table 1, was determined.
Table 1: Toque for various arm joints

\begin{tabular}{|c|r|r|c|c|}
\hline & \multicolumn{4}{|c|}{ DESCRIPTION } \\
\hline Motor Location & \multicolumn{1}{|c|}{ Base } & Shoulder & Elbow & Wrist \\
\hline Torque $(\mathrm{Nm})$ & 0.0031 & 0.8049 & 0.5496 & 0.000322 \\
\hline
\end{tabular}

Table 2 shows the specification of the motors that were selected. They all have torque that is greater than the (required) calculated torque. We decided to use the same type of motor for the shoulder and elbow although the elbow could accommodate a small motor. We also used a similar motor for the wrist despite very low torque requirement. We did this because the motor was physically small enough, and using similar motors on the robotic arm makes it easier to keep the inventory of spares.

Table 2: Specification of Selected Motors

\begin{tabular}{|c|c|c|c|}
\hline FEATURE & \multicolumn{3}{|c|}{ DESCRIPTION } \\
\hline Motor & $\begin{array}{l}\text { HS-5055MG } \\
\text { Servo motor for } \\
\text { gripper/base }\end{array}$ & $\begin{array}{l}\text { HS-5485HB } \\
\text { Servo motor for } \\
\text { shoulder/ elbow }\end{array}$ & $\begin{array}{l}\text { HS-5485HB } \\
\text { Servo motor for } \\
\text { wrist }\end{array}$ \\
\hline Voltage $(\mathrm{V})$ & 6.0 & 6.0 & 6.0 \\
\hline Torque $(\mathrm{Nm})$ & $0 . .5$ & 1.11 & 1.11 \\
\hline Speed $(\mathrm{Rad} / \mathrm{s})$ & 5.236 & 5.236 & 5.236 \\
\hline Span $($ degrees) & 90 & 90 & 180 \\
\hline
\end{tabular}

Table 3 shows the cost associated with the various motors that we selected.

Table 1: Cost of Robotic Arm Motors

\begin{tabular}{|l|l|l|l|}
\hline QTY & \multicolumn{1}{|c|}{ PART DESCRIPTION } & UNIT PRICE & AMOUNT (\$) \\
\hline 1 & $\begin{array}{l}\text { HS-5055MG Servo Motor }\left(90^{\circ}\right) \\
\text { for the gripper }\end{array}$ & 17.99 & 17.99 \\
\hline 3 & HS-5485HB Servo Motor $\left(90^{\circ}\right)$ & 24.99 & 74.97 \\
\hline 1 & $\begin{array}{l}\text { HS-5485HB Servo Motor }\left(180^{\circ}\right) \\
\text { for wrist joint }\end{array}$ & 34.99 & 34.99 \\
\hline $\begin{array}{l}\text { All motors have operating speed of } \\
0.20 \text { sec } 60^{\circ}\left(5.236 \mathrm{rad} / \mathrm{s}^{\circ} \text { at } 6.0 \mathrm{VDC}\right.\end{array}$ & SUBTOTAL & 127.95 \\
\hline
\end{tabular}

\subsection{Electrical Design}

This is one of the design components that fall under the scope of the Industrial Networks and Controllers course. Students start the electrical design by establishing the design criteria just as we did during the mechanical design phase. Such criteria may include:

- Maximizing production.

- Minimizing energy consumption.

- Optimizing cost of making robot.

- Optimizing functionality.

These criteria are used in the selection of components, evaluation of electrical design option, and analysis of the electrical designs.

During the detailed design phase, students analyze their designs to ensure that they meet the design criteria, 
and do not violate the electrical specification of the system components. Figure 2 shows an example of calculations that may be carried out to determine battery life of the robotic arm. Such a calculation would help the designers to determine how a design performs against the energy design criterion.

$$
\begin{gathered}
P_{\text {total }}=P_{\text {motor }}+P_{\text {mitcrerontroller }} \\
P_{\text {totat }}=4.21+(3.3 \mathrm{~V} \times 60 \mathrm{~mA} \times 0.001) \\
P_{\text {total }}=4.41 \mathrm{~W} \\
I=\frac{P_{\text {total }}}{V} \\
I=\frac{4.41 \mathrm{~W}}{6.0 \mathrm{~V}} \\
I=0.735 \mathrm{~A} \\
\therefore \text { Battery Life }=\frac{22 \mathrm{~mA} \times 11 \text { hours }}{0.735 \mathrm{~A}} \times \frac{1}{1000} \\
\text { Battery Life }=2.99 \text { hours }
\end{gathered}
$$

Fig. 2. Calculation of Battery Life of the Robotic Arm.

Note that the calculation in Figure 2 was based on the following assumptions:

- $\quad$ The device operates on $8,1.5 \mathrm{~V}$ batteries.

- The batteries used are similar to the Duracell MN1500 pack.

- The Duracell pack operates at $200 \mathrm{~mA}$ for 11 hour and decays to $1.0 \mathrm{~V}$.

- Microcontroller operates continuously at maximum current of $60 \mathrm{~mA}$.

\subsection{Software Design}

Like the mechanical and electrical design phases, the software design starts by establishing the design criteria. These criteria have to address the sequence of activities performed by the robotic arm. Moreover, the software design is affected by the electrical devices, hence it is important to start the software design process before final decisions are made on the selection of electrical devices. This is something that students learn as they carry out this project.

\section{USING THE ROBOTIC ARM IN AN INTEGRATED DESIGN PROJECT}

Our integrated design project is carried out within the paradigm of integrating lectures, laboratories and course projects [9]. Material on microcontrollers, sensors, actuators and interfaces is first presented to students through lectures. These lectures include some small group discussions and class quizzes or take home assignments.
Thereafter, students do laboratory work in microcontroller programming where they interface microcontrollers with various types of sensors and actuators. The material covered in lectures and in laboratories is directly applicable in the integrated design project since the Industrial Networks and Controllers course focuses on the electrical and software design of the robotic arm.

We carried out the mechanical design and developed a solid work file for the 3D printable robotic arm shown in Figure 3a. We also documented the mechanical design process in a mechanical design report. Therefore, at the beginning of the project we give students the solid works file of the robotic arm and the mechanical design report which has the mechanical specification of the arm and the associated cost. This information gives an insight into the mechanical design process and helps them to decide whether to use our design, switch out the motors in our design, or buy different robotic arms that meet the mechanical design criteria of our arm.

When we carried out a pilot study of our project one participant preferred to use our design while another suggested buying one of the robots shown in Figures $3 \mathrm{~b}$ and $3 \mathrm{c}$. Moreover, some participants preferred analog servo motors while other wanted to use digital servos.

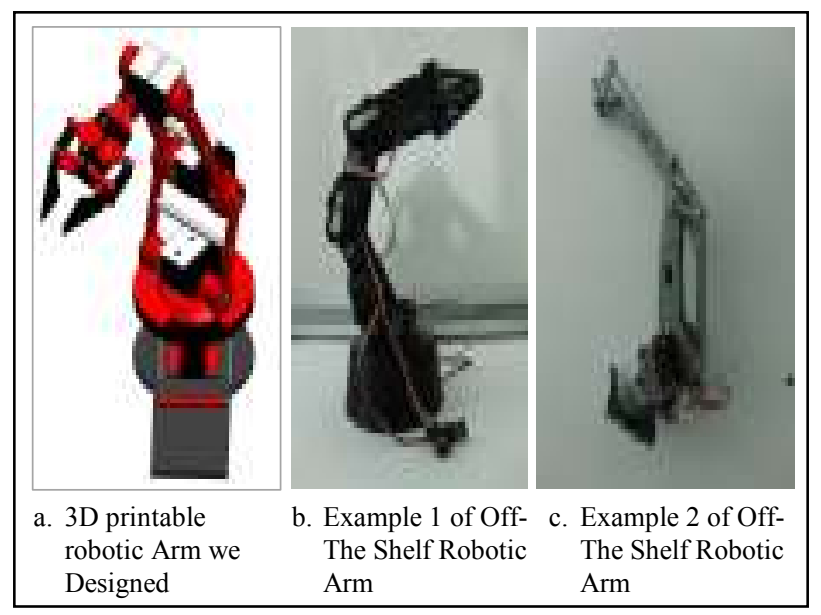

Fig.3. Robotic Arm.

\section{CONCLUSION}

It is generally agreed in the academia that most people learning better by doing $[2,8,10]$. However, due to cost and time constraints, it is difficult to run full hands on integrated design projects. This has motivated us to develop an integrated design project that focuses on the learning outcomes of a process automation program, while giving students insight into related design areas that affect their products. A pilot study of our project showed that although we give students the mechanical design of the 
robot, the project remains open-ended, allowing students to make their own design choices and learn immensely from the process. In the future we would like to carry out a formal study on the educational effectiveness of this project.

\section{References}

[1] Angel Soriano, Leonardo Marin, Marina Valles, Angel Valera, Pedro Albertos, "Low Cost Platform for Automatic Control Education Based on Open Hardware", The International Federation of Automatic Control, IFAC 2014, Edward Boje and Xiaohua Xia (ed), (Cape Town, South Africa; 24-29 August 2014), 904pp., 2014.

[2] Bradley S. Barker and John Ansorge, "Robotics as Means to Increase Achievement Scores in an Informal Learning Environment", Journal of Research on Technology in Education, Vol. 39, no. 3, pp. 229-243, 2007. Available as of April $5^{\text {th }}, 2015$ from

http://education.rec.ri.cmu.edu/content/educators/research/f iles/Robotics\%20As\%20Means $\% 20$ To\%20Increase $\% 20$ Ac hievement $\% 20$ Score.pdf

[3] Gregorio Juliana, Álvaro Rodríguez, Hugo Ramos, "Development of a multi-purpose, modular, low cost robotic arm for education and unmanned platforms", Available at http://www.eurathlon.eu, Accessed on May 14th, 2014.

[4] Igor M. Verner and Evgeny Korchnoy, "Experiential Learning through Designing Robots and Motion Behaviors: A Tiered Approach", International Journal of Engineering Education, Vol. 22, no. 4, pp. 758-765, 2006. Available as of April 5 $5^{\text {th }}, 2015$ from http://www.ijee.ie/articles/Vol224/07_ijee1800.pdf

[5] Jennifer Kadlowec, Paris von Lockette, Eric Constans, Beena Sukumaran, Douglas Cleary, "Hands-on Learning
Tools for Engineering Mechanics", In Proc. of the 2002 American Society for Engineering Education Annual Conference, (Montreal, Quebec; June 2002

[6] Mir Sajjad Hussain Talpur and Murtaza Hussain Shaikh, "Automation of Mobile Pick and Place Robotic System for Small food Industry", Journal of Institution of Electrical \& Electronics Engineers, Vol 1139-8, no. 12, pp 584 - 588, 2012. Available as of April $5^{\text {th }}, 2015$ from http://arxiv.org/ftp/arxiv/papers/1203/1203.4475.pdf .pdf

[7] Puran Singh, Anil Kumar, Mahesh Vashisth, "Design of a Robotic Arm with Gripper \& End Effector for Spot Welding”, Universal Journal of Mechanical Engineering, Vol. 1, no. 3, pp. 92-97, 2013. Available as of April $5^{\text {th }}$, 2015 from http://www.hrpub.org/download/201310/ujme.2013.01030 3

[8] Reiner Schmidt, Tom Wanyama, and Ishwar Singh, "Teaching Integrated System Design: Case of Mechatronics Project based on a Line-Following Robot", In Proc. of the International Conference on Engineering Education and Research, ICEER2014, Mohamed Bakr and Ahmed Elsharabasy (ed) (Hamilton, Ontario; Canada, 25-26 August 2014), 23 pp., 2014.

[9] Tom Wanyama, and Ishwar Singh, "Integrating Lectures, Laboratories and Course Projects", In Proc. of the International Conference on Engineering Education and Research, ICEER2014, Mohamed Bakr and Ahmed Elsharabasy (ed) (Hamilton, Ontario; Canada, 25-26 August 2014), 34 pp., 2014.

[10] Yves Piguet, Francesco Mondada, Roland Siegwart, “"Hands-On Mechatronics": Problem-Based Learning for Mechatronics", In Proc. of the IEEE International Conference on Robotics and Automation, (Washington D.C.; USA, 11-15 May, 2002). 7-CEEA2014 